\title{
Divisibilty of Selected Primes and the Number Generator Method
}

\author{
Shreyan Mondal, \\ Department of Applied Physics, Delhi Technological University (formerly Delhi College of Engineering), Delhi)
}

\begin{abstract}
The research paper aims to determine the divisibility's of a fixed set of common primes namely 7,11,13,17,23,29,31,43,47,43,89\& 97 via the compartment method. The method initially during its foundation was extended to 7 but was later successfully extended to the remaining selected numbers. Number Trials (divisibility checker) provide an impetus to check the validation of the compartment method. In spite of the intricacies entailed by the proposed method it successfully aids in determining the divisibilities of other numbers (composites also) as well. An extension to the Number Generator Method has been made to encryption \& code generation employing the usage of the former \& Euler's Totient function on a primary level.

Keywords: Divisibility, Compartment method, Primes, Number Generator method,Euler-Totient,Greatest Integer Function
\end{abstract}

\section{The Compartment Method}

Statement: A given number $\mathrm{X}$ is divisible by the given prime ' $\mathrm{N}$ ' if that number is divided into compartments starting from the right where each compartment contains 2 digits. The last compartment on the left may contain a single or a double digit depending on the numbers of digits in the number. Each of the compartments are multiplied by consecutively increasing powers of the multiplying factor. The products obtained are summed up. The number obtained has a sum less than the original number. The above stated operations are carried out on the number till the sum is reduced to 2 digit number. If the 2 -digit number obtained is divisible by the prime or a multiple of the prime such that it is less than 100, then the original number is divisible by the prime ' $N$ ' whose divisibility was to be checked.

Corollary 1: Consider a number $X$ where $X$ is expressed as $a_{n} a_{n-1} a_{n-2} a_{n-3} \ldots \ldots \ldots \ldots \ldots a_{2} a_{1} \quad$ where $a_{n-1}$ represents the nth of the number $\mathrm{a}_{\mathrm{n}-1} \quad$ represents the $\mathrm{n}-1$ digit of the number ......... and so on $\begin{array}{cccccc}a_{2} & \text { represents } & \text { the } & 2^{\text {nd }} & \text { digit } & \text { of }\end{array}$ the number $\begin{array}{lllll}\mathrm{a}_{1} & \text { represents } & 1^{\text {st }} \text { the } & \text { digit } & \text { of }\end{array}$ Let $\mathrm{n}$ be even. According to the statement of the compartment method, $\mathrm{x}$ is divided into compartments as follows :-

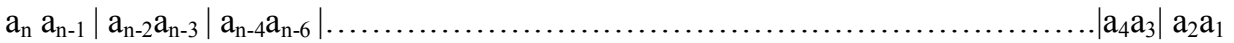

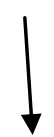

$(\mathrm{n} / 2)$ th compartment

For digits there are $n$ (n/2) compartments. If $\mathrm{n}$ is odd then number of compartments are $(n+1) . / 2$. Let $\mathrm{Y}$ be an operator performed on $\mathrm{X}$. Symbolically it is denoted as $\mathrm{Yk} \mid \mathrm{X}$ where $\mathrm{k}$ denotes the multiplying factor. To check the divisibility by 7 , the given number is multiplied by increasing powers of 2 . The table below summarises some numbers whose divisibility is to be checked ( the value of $\mathrm{N}$ ) and their corresponding multiplying factors $(\mathrm{K})$.

\begin{tabular}{|l|l|l|l|l|l|l|}
\hline $\mathrm{N}$ & 11 & 7 & 97 & 19 & 47 & 31 \\
\hline $\mathrm{K}$ & 1 & 2 & 3 & 5 & 6 & 7 \\
\hline
\end{tabular}

Table1(a)

\begin{tabular}{|l|l|l|l|l|l|l|}
\hline $\mathrm{N}$ & 23 & 13 & 89 & 29 & 43 & 17 \\
\hline $\mathrm{K}$ & 8 & 9 & 11 & 13 & 14 & 15 \\
\hline
\end{tabular}

Table1(b)

PROOF: Consider the number $\mathrm{X}$ as:-

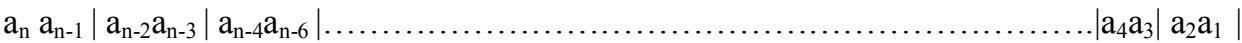

Using Greatest integer function, [] the last 2 digits namely $a_{n} a_{n-1}$ and all the digits in the compartment can be represented as:- $a_{n} a_{n-1}=\left[X . / 10 .^{\wedge}(n-2)\right]$ the $2^{\text {nd }}$ last digits can be represented as:- $\left[\mathrm{X} . / 10 .^{\wedge}(\mathrm{n}-4)\right]-\left(\left[\mathrm{X} . / 10 .^{\wedge}(\mathrm{n}-2)\right]^{*} 10 .^{\wedge} 2\right)$; Similarly 
the $3^{\text {rd }}$ last digits can be represented as : $\left[\mathrm{X} . / 10 .^{\wedge}(\mathrm{n}-6)\right]-\left(\left[\mathrm{X} . / 10 .^{\wedge}(\mathrm{n}-4)\right]^{*} 10 \wedge^{\wedge} 2\right)$ and so on. $\mathrm{a}_{4} \mathrm{a}_{3} \quad$ can represented as :- $\left[\mathrm{X} . / 10 . \wedge^{\wedge}\right]-\left(\left[\mathrm{X} . / 10 . \wedge^{\wedge} 4\right]^{*} \quad 10 .^{\wedge} 2\right)$; and the first compartment $\mathrm{a}_{2} \mathrm{a}_{1}$ is represented as: - $\mathrm{X}-\left(\left[\mathrm{X} . / 10 .^{\wedge} 2\right]^{*} 10 .^{\wedge} 2\right)$;

Applying operator $Y$ on the number $X$, for checking the divisibility of $X$, from the table with $N=7$ we get $k=2$ $:-$

$2 .^{\wedge}\left(0.5^{*} \mathrm{n}-1\right)^{*}\left[\mathrm{X} . / 10 .^{\wedge}(\mathrm{n}-2)\right]+2^{\wedge}\left(0.5^{*} \mathrm{n}-2\right)^{*}\left(\left[\mathrm{X} . / 10{ }^{\wedge}(\mathrm{n}-4)\right]-\left(\left[\mathrm{X} . / 10 .{ }^{\wedge}(\mathrm{n}-2)\right]^{*} 10 .^{\wedge} 2\right)\right)+$ 2. ${ }^{\wedge}\left(0.5^{*} \mathrm{n}-3\right)^{*}\left(\left[\mathrm{X} . / 10 .^{\wedge}(\mathrm{n}-6)\right]-\left(\left[\mathrm{X} . / 10 .^{\wedge}(\mathrm{n}-4)\right]^{*} 10 .^{\wedge} 2\right)\right)$

10.^2)

$.2 *\left([X . / 10 . \wedge 2]-\left(\left[X . / 10 .^{\wedge} 4\right]^{*} 10 . \wedge 2\right)\right)+X-\left([X . / 10 . \wedge 2]^{*}\right.$

Now collecting similar powers of $2 \wedge^{\wedge}\left(0.5^{*} \mathrm{n}-1\right) \quad$ where $\mathrm{l}=1,2,3, \ldots \ldots \ldots \ldots \ldots \ldots, 0.5^{*} \mathrm{n} \quad(\mathrm{n}$ is strictly even $)$

$2 .^{\wedge}\left(0.5^{*} \mathrm{n}-2\right)^{*}\left[\mathrm{X} . /\left(10 .^{\wedge}(\mathrm{n}-2)\right)\right]^{*}\left(2-10 . .^{\wedge}\right)+2 .^{\wedge}\left(0.5^{*} \mathrm{n}-3\right)^{*}\left[\mathrm{X} . /\left(10 .^{\wedge}(\mathrm{n}-4)\right)\right]^{*}\left(2-10 .^{\wedge} 2\right)+$

$2 .^{\wedge}(0.5 * \mathrm{n}-5) *\left[\mathrm{X} . /\left(10 .^{\wedge}(\mathrm{n}-6)\right)\right] *\left(2-10 . \wedge^{\wedge}\right)+$

$+[\mathrm{X} . / 100] *(2-10 . \wedge 2)+\mathrm{X}$

Collecting the term $\left(2-10 \wedge^{\wedge} 2\right)=-98$ and writing 98 as $2 * 7 . \wedge 2$ outside the brackets we get

$\mathrm{X}-2 * 7 . .^{\wedge} *\left(2^{\wedge}\left(0.5^{*} \mathrm{n}-2\right)^{*}\left[\mathrm{X} . / 10 .^{\wedge}(\mathrm{n}-2)\right]+2 .^{\wedge}\left(0.5^{*} \mathrm{n}-3\right) *\left(\left[\mathrm{X} . / 10 .{ }^{\wedge}(\mathrm{n}-\right.\right.\right.$

$\left.4)]+\ldots \ldots \ldots \ldots \ldots \ldots \ldots \ldots \ldots \ldots+\left[\mathrm{X} . / 10 . \wedge^{2}\right]\right)$

Now consider 2 cases: Case1: If $\mathrm{X}$ is divisible by 7 , it can be expressed in the form of $\mathrm{x}=7 * \mathrm{~m}(\mathrm{~m} \varepsilon \mathrm{N}$ where

$\mathrm{N}$ is the set of natural numbers), the (1) above becomes:-

$7 *\left(m-14^{*}\left(2^{\wedge}\left(0.5^{*} \mathrm{n}-2\right) *\left[\mathrm{X} . / 10 .^{\wedge}(\mathrm{n}-2)\right]+2 .^{\wedge}\left(0.5^{*} \mathrm{n}-3\right) *\left(\left[\mathrm{X} . / 10 .^{\wedge}(\mathrm{n}-4)\right]+\right.\right.\right.$

$\left.\left[\mathrm{X} . / 10 .{ }^{\wedge} 2\right]\right)$;

(2) is clearly divisible by 7 .

Case 2: If $X$ is not divisible by 7 then let $X$ be represented as $X=7 * p+q$, then (1) becomes.

$7 *\left(\mathrm{p}-14^{*}\left(2^{\wedge}\left(0.5^{*} \mathrm{n}-2\right) *\left[\mathrm{X} . / 10 .^{\wedge}(\mathrm{n}-2)\right]+2 .^{\wedge}\left(0.5^{*} \mathrm{n}-3\right)^{*}\left(\left[\mathrm{X} . / 10 .^{\wedge}(\mathrm{n}-4)\right]+\right.\right.\right.$

$[X . / 10 . \wedge 2]))+q$

The summation appearing before $\mathrm{q}$ is divisible by 7 but since $\mathrm{q}$ is less than 7 , the entire sum is not divisible by 7 .

\section{Number Trials}

Consider the number $\mathrm{X}=6284056464$, by actual division we can easily find that : $(6284056464 / 7)=897722352 ;$ By applying the compartment method on this number we get ;

$62|84| 05|64| 64=5$ compartments, which implies multiplication is to be performed till $2{ }^{\wedge} 4=16$

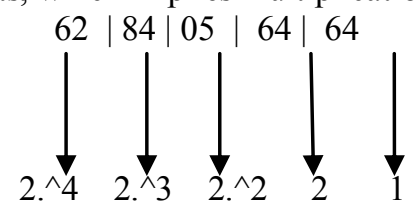

This gives:- $16 * 62+84 * 8+5 * 4+64 * 2+64=992+672+20+128+64=1876$ where the number obtained after performing the $\mathrm{Y}$ operator on $\mathrm{X}$ is much less than $\mathrm{X}$. This supports the statement validating the compartment method. Again performing the operation on $1876 \ldots .$.

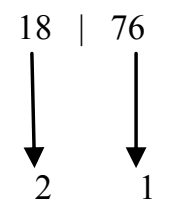

This gives $18 * 2+76=112$ again validating the compartment method statement. Performing the operation on 112 gives:-

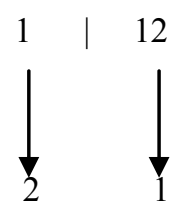

This gives $2 * 1+12=14$. As 14 is clearly divisible by 7 method 6284056464 is divisible by 7 which validates the proof....

Consider the $\mathrm{X}=975433$, By applying the compartment method $97|54| 33=3$ compartments, implies multiplication is to be performed till $2 . \wedge 2=4$;

$97|54| 33$

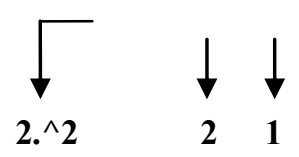


This gives: $-97 * 4+54 * 2+33=529$ where the number obtained by performing operator $\mathrm{Y}$ on $\mathrm{X}$ is much less than $\mathrm{X}$ thereby supporting the statement validating the compartment method. Again performing the operation on 529

5 | 29

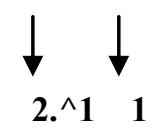

This gives:- $5^{*} 2+59=39$, as the sum finally reduces to a 2 digit number. As 39 is not divisible by 7 , so isn't 975433 . It can be confirmed that $975433 / 7=139347.57$ which again validates the proof. Similarly these trials can be performed for the other set of numbers enlisted in table1(a) \& table1(b).

\section{Generalised Proof For A Fixed Set Of Primes}

In the proof above we had devised the technique to check the divisibility of 7 . For checking the divisibility of $\mathrm{X}$ with the prime $\mathrm{N}$ from the fixed set:-

Consider $X=a_{n} a_{n-1} a_{n-2} a_{n-3} \ldots \ldots \ldots \ldots a_{2} a_{1}$

Using the Greatest Integer function [] to represent the digits of each compartment:-

$$
\mathrm{a}_{\mathrm{n}} \mathrm{a}_{\mathrm{n}-1}=\left[\mathrm{X} . / 10 .^{\wedge}(\mathrm{n}-4)\right]-\left(\left[\mathrm{X} . / 10 .^{\wedge}(\mathrm{n}-2)\right]^{*} 10 .^{\wedge} 2\right)
$$

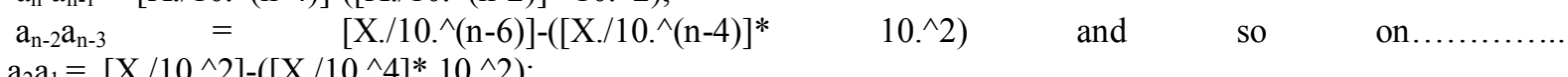
$\mathrm{a}_{2} \mathrm{a}_{1}=\left[\mathrm{X} . / 10 .^{\wedge} 2\right]-\left(\left[\mathrm{X} . / 10 .^{\wedge} 4\right]^{*} 10 .^{\wedge} 2\right)$

Multiplying $\mathrm{X}$ with $\mathrm{Y}$ operator with a multiplying factor ' $\mathrm{k}$ ', we get:-

$a_{n} a_{n-1}\left|a_{n-2} a_{n-3}\right| a_{n-4} a_{n-6} \mid$ $.\left|a_{4} a_{3}\right| a_{2} a_{1} \mid$
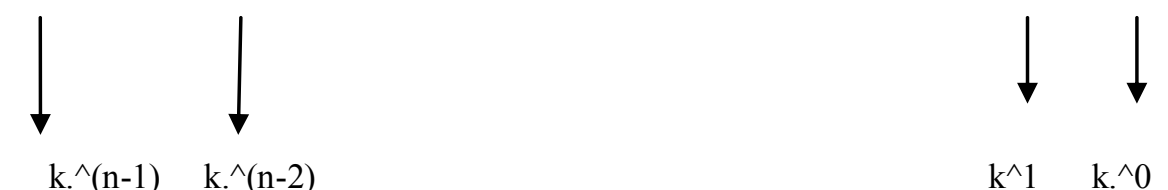

$\mathrm{k} \cdot{ }^{\wedge}(\mathrm{n}-1) \quad \mathrm{k} \cdot{ }^{\wedge}(\mathrm{n}-2)$

$\mathrm{k}^{\wedge} 1 \quad \mathrm{k} \cdot{ }^{\wedge} 0$

$\mathrm{k} . \wedge\left(0.5^{*} \mathrm{n}-1\right)^{*}\left[\mathrm{X} . / 10 .^{\wedge}(\mathrm{n}-2)\right]+\mathrm{k} . .^{\wedge}\left(0.5^{*} \mathrm{n}-2\right) *\left(\left[\mathrm{X} . / 10 .^{\wedge}(\mathrm{n}-4)\right]-\left(\left[\mathrm{X} . / 10 .^{\wedge}(\mathrm{n}-2)\right]^{*} 10 . .^{\wedge}\right)+\right.$ k. $.^{\wedge}\left(0.5^{*} \mathrm{n}-3\right) *\left(\left[\mathrm{X} . / 10 .^{\wedge}(\mathrm{n}-6)\right]-\left(\left[\mathrm{X} . / 10 .^{\wedge}(\mathrm{n}-4)\right]^{*} 10 .{ }^{\wedge} 2\right)\right)+$

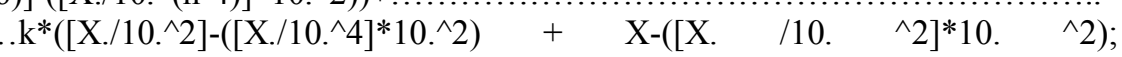
-(iii)

Selecting the corresponding values of $\mathrm{K}$ for different values of $\mathrm{N}$ from table1(a) \& table1(b)

PARTICULAR CASES

Case 1: For $\mathrm{N}=11, \mathrm{~K}=1$; hence (iii) becomes;

$\Longrightarrow \mathrm{X}-99 *\left(\left[\mathrm{x} . / 10 .^{\wedge}(\mathrm{n}-2)\right]+\left[\mathrm{X} . / 10 .^{\wedge}(\mathrm{n}-4)\right]+\left[\mathrm{X} . / 10 .^{\wedge}(\mathrm{n}-6)\right]+\ldots\right.$

Decomposing 99 as $11 * 9$ we get;

$\mathrm{X}-11 * 9 *\left(\left[\mathrm{X} . / 10 .^{\wedge}(\mathrm{n}-2)\right]+\left[\mathrm{X} . / 10 .^{\wedge}(\mathrm{n}-4)\right]+\left[\mathrm{X} . / 10 .^{\wedge}(\mathrm{n}-6)\right]+\right.$

This is clearly divisible by 11 if $\mathrm{X}$ can be expressed in the form $\mathrm{X}=11^{*}$ where 1 is a natural number Case2: For $\mathrm{N}=7, \mathrm{~K}=2$; hence (iii) becomes;

$\Longrightarrow \mathrm{X}+\left[\mathrm{X} . / 10 .^{\wedge}(\mathrm{n}-2)\right]^{*} 2 .^{\wedge}\left(0.5^{*} \mathrm{n}-2\right)^{*}\left(2-10 .^{\wedge} 2\right)+\left[\mathrm{X} . / 10 .^{\wedge}(\mathrm{n}-4)\right]^{*} 2 .^{\wedge}\left(0.5^{*} \mathrm{n}-3\right) *\left(2-10 .^{\wedge} 2\right)+\left[\mathrm{X} . / 10 .^{\wedge}(\mathrm{n}-6)\right]^{*} 2 .^{\wedge}\left(0.5^{*} \mathrm{n}-\right.$

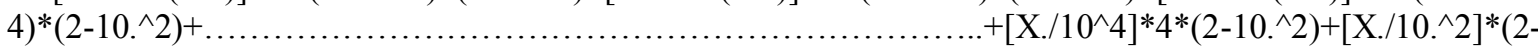
10.^2)

Taking $\left(2-10 .^{\wedge} 2=-98=-2 * 49=-2 * 7 . \wedge 2\right)$ as common factor $\&$ rearranging

$\Rightarrow \mathrm{X}-2^{*} 7 .^{\wedge} 2^{*}\left(\left[\mathrm{X} . / 10 .^{\wedge}(\mathrm{n}-2)\right]+\left[\mathrm{X} . / 10 .^{\wedge}(\mathrm{n}-4)\right]+\left[\mathrm{X} . / 10 .^{\wedge}(\mathrm{n}-6)\right]+\right.$

$\left.\left[\mathrm{X} . / 10 .^{\wedge} 4\right]+\left[\mathrm{X} . / 10 .^{\wedge} 2\right]\right)$

This is clearly divisible by 7 if $\mathrm{X}$ can be expressed in the form $\mathrm{X}=7 * \mathrm{~L}$ where $\mathrm{L}$ is natural .

Case 3: for $\mathrm{K}=3, \mathrm{~N}=97$; hence (iii) becomes;

$\Longrightarrow \mathrm{X}+\left[\mathrm{X} . / 10 .^{\wedge}(\mathrm{n}-2)\right]^{*}\left(3-10 .^{\wedge} 2\right)^{*} 3 .^{\wedge}\left(0.5^{*} \mathrm{n}-2\right)+$

$10 . \wedge 2)^{*} 3 .^{\wedge}\left(0.5^{*} \mathrm{n}-4\right)+$

$\left[\mathrm{X} . / 10 .^{\wedge}(\mathrm{n}-4)\right]^{*}\left(3-10 . .^{\wedge}\right) * 3 .^{\wedge}\left(0.5^{*} \mathrm{n}-3\right)+\quad\left[\mathrm{X} . / 10 .^{\wedge}(\mathrm{n}-6)\right]^{*}(3-$

$\left[\mathrm{X} . / 10 .^{\wedge} 4\right]^{*}\left(3-10 .{ }^{\wedge} 2\right)^{*} 3+\left[\mathrm{X} . / 10 .^{\wedge} 2\right]^{*}\left(3-10 .^{\wedge} 2\right)$

Taking out $(3-10 . \wedge 2=-97)$ as common $\&$ rearranging

$\mathrm{X}-97 *\left(\left[\mathrm{x} . / 10 .^{\wedge}(\mathrm{n}-2)\right]+\left[\mathrm{X} . / 10 .^{\wedge}(\mathrm{n}-4)\right]+\left[\mathrm{X} . / 10 .^{\wedge}(\mathrm{n}-6)\right]+\right.$ .[X./10.^2]);

This is clearly divisible by 97 if $X$ can be expressed of the form $X=97^{*} \mathrm{~L}$, where $\mathrm{L}$ is a natural number Case 4: For $\mathrm{K}=5, \mathrm{~N}=19$; hence (iii) becomes 
Decomposing $95=19 * 5 \&$ substituting in the above expansion

$\mathrm{X}-95^{*}\left(\left[\mathrm{x} . / 10 \wedge^{\wedge}(\mathrm{n}-2)\right]+\left[\mathrm{X} . / 10 \wedge^{\wedge}(\mathrm{n}-4)\right]+\left[\mathrm{X} . / 10 .^{\wedge}(\mathrm{n}-6)\right]+\right.$ ...X./10.^2]);

This is clearly divisible by 19 if $\mathrm{X}$ can be expressed as $\mathrm{X}=19 * \mathrm{~L}$ where $\mathrm{L}$ is a natural number

Case 5: For $\mathrm{K}=6, \mathrm{~N}=47$; hence (iii) becomes

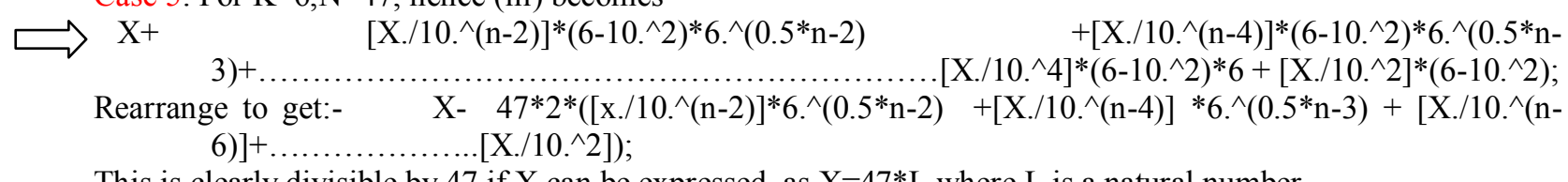

This is clearly divisible by 47 if $\mathrm{X}$ can be expressed as $\mathrm{X}=47 * \mathrm{~L}$ where $\mathrm{L}$ is a natural number

Case 6: For $\mathrm{K}=7, \mathrm{~N}=31$; hence (iii) becomes

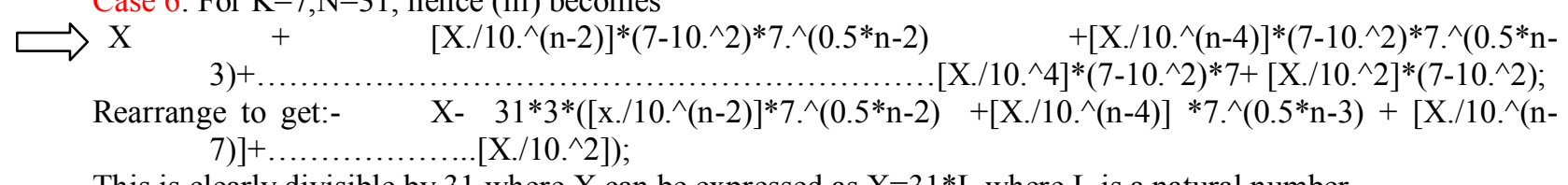

This is clearly divisible by 31 where $\mathrm{X}$ can be expressed as $\mathrm{X}=31 * \mathrm{~L}$ where $\mathrm{L}$ is a natural number

Case 7: For $\mathrm{K}=8, \mathrm{~N}=23$; hence (iii) becomes

$\mathrm{X}+\left[\mathrm{X} . / 10 .^{\wedge}(\mathrm{n}-2)\right]^{*}(8-10 . \wedge 2)^{*} 8 .^{\wedge}\left(0.5^{*} \mathrm{n}-2\right)+$ $3)+\ldots \ldots \ldots \ldots \ldots \ldots \ldots \ldots \ldots \ldots \ldots \ldots \ldots \ldots . . . \ldots . / 10 . \wedge 4]^{*}(8-10 . \wedge 2) * 8+\left[\mathrm{X} . / 10 .{ }^{\wedge} 2\right]^{*}\left(8-10{ }^{\wedge} 2\right)$;

$\left[\mathrm{X} . / 10 .^{\wedge}(\mathrm{n}-4)\right]^{*}\left(8-10 .{ }^{\wedge} 2\right) * 8 .^{\wedge}\left(0.5^{*} \mathrm{n}-\right.$

Taking out $8-10 . \wedge 2=-92=-23 * 4$ as common to get :-

$\mathrm{X}-23 * 4 *\left(\left[\mathrm{X} . / 10 .^{\wedge}(\mathrm{n}-2)\right]+\left[\mathrm{X} . / 10 .^{\wedge}(\mathrm{n}-4)\right]\right.$

$+\left[\mathrm{X} . / 10 .^{\wedge}(\mathrm{n}-6)\right]+$

$\left.+\left[\mathrm{X} . / 10 \wedge^{\wedge} 4\right]+\left[\mathrm{X} . / 10 . \wedge^{\wedge}\right]\right)$

This is clearly divisible by 23 if $\mathrm{X}$ can be expressed as $\mathrm{X}=23 * \mathrm{~L}$ where $\mathrm{L}$ is a natural number

Case 8: For $\mathrm{K}=9, \mathrm{~N}=13$; hence (iii) becomes:-

$\Longrightarrow \mathrm{X}+\left[\mathrm{X} . / 10 .^{\wedge}(\mathrm{n}-2)\right]^{*}\left(9-10 . .^{\wedge}\right)^{*} 9 . \wedge\left(0.5^{*} \mathrm{n}-2\right)+$

$\left[\mathrm{X} . / 10 .^{\wedge}(\mathrm{n}-4)\right]^{*}\left(9-10 .^{\wedge} 2\right) * 9 .^{\wedge}\left(0.5^{*} \mathrm{n}-\right.$

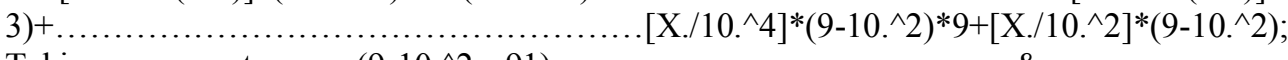

Taking out $\left(9-10 \wedge^{\wedge} 2=-91\right)$ as common \& rearrange to get:-

$\mathrm{X}-13 * 7 *\left(\left[\mathrm{X} . / 10 .^{\wedge}(\mathrm{n}-2)\right]+\left[\mathrm{X} . / 10 .^{\wedge}(\mathrm{n}-4)\right]\right.$

$+[\mathrm{X} . / 10 . \wedge(\mathrm{n}-6)]+$

$\left..+\left[X . / 10 .^{\wedge} 4\right]+\left[X . / 10 .^{\wedge} 2\right]\right)$

Clearly this is divisible by 13 if $\mathrm{X}$ can be expressed as $\mathrm{X}=13 * \mathrm{~L}$ where $\mathrm{L}$ is natural number

Case 9: For $\mathrm{K}=11, \mathrm{~N}=89$; hence (iii) becomes:-

$\Longrightarrow \mathrm{X}+\left[\mathrm{X} . / 10 \wedge^{\wedge}(\mathrm{n}-2)\right]^{*}\left(11-10 .^{\wedge} 2\right)^{*} 11 .^{\wedge}\left(0.5^{*} \mathrm{n}-2\right)$

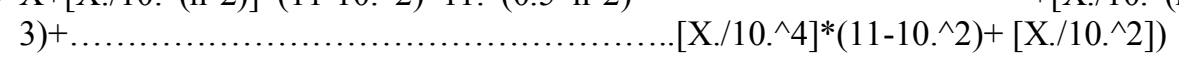

$+\left[\mathrm{X} . / 10 .^{\wedge}(\mathrm{n}-4)\right]^{*}\left(11-10 .^{\wedge} 2\right)^{*} 11 .^{\wedge}\left(0.5^{*} \mathrm{n}-\right.$

Rearrange to get by taking $\left(11-10 .^{\wedge} 2\right)$ as common factor

$\mathrm{X}-89 *\left(\left[\mathrm{X} . / 10 .^{\wedge}(\mathrm{n}-2)\right]+\left[\mathrm{X} . / 10 .^{\wedge}(\mathrm{n}-4)\right]+\left[\mathrm{X} . / 10 .^{\wedge}(\mathrm{n}-6)\right]+\right.$

.............. [X./10.^4]+[X./10.^2])

Clearly this is divisible by 89 if $\mathrm{X}$ can be expressed as $\mathrm{X}=89 * \mathrm{~L}$;

Case 10: For $\mathrm{K}=13, \mathrm{~N}=29$; hence (iii) becomes:-

$\mathrm{X}+\left[\mathrm{X} . / 10 \wedge^{\wedge}(\mathrm{n}-2)\right]^{*}\left(13-10 .^{\wedge} 2\right)^{*} 13 .^{\wedge}\left(0.5^{*} \mathrm{n}-2\right)$

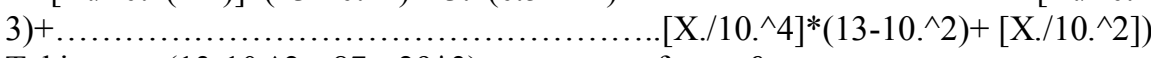

Taking out $\left(13-10 .^{\wedge} 2=-87=-29 * 3\right)$ as common factor $\&$ rearrange to get

$>\mathrm{X}-29 * 3 *\left(\left[\mathrm{X} . / 10 .^{\wedge}(\mathrm{n}-2)\right]+\left[\mathrm{X} . / 10 .^{\wedge}(\mathrm{n}-3)\right]+\left[\mathrm{X} . / 10 .^{\wedge}(\mathrm{n}-4)\right]+\right.$

............................ $\left.+\left[\mathrm{X} . / 10{ }^{\wedge} 4\right]+[\mathrm{X} . / 10 . \wedge 2]\right)$

Clearly this is divisible by 13 if $\mathrm{X}$ can be expressed as $\mathrm{x}=13 * \mathrm{~L}$ where $\mathrm{L}$ is a natural number.

Case 11: For $\mathrm{K}=14, \mathrm{~N}=43$; hence (iii) becomes

$>\mathrm{X}+\left[\mathrm{X} . / 10 .^{\wedge}(\mathrm{n}-2)\right]^{*}\left(14-10 .{ }^{\wedge} 2\right)^{*} 14 .{ }^{\wedge}\left(0.5^{*} \mathrm{n}-2\right)+\left[\mathrm{X} . / 10 .{ }^{\wedge}(\mathrm{n}-4)\right]^{*}\left(14-10 .{ }^{\wedge} 2\right) * 14 .^{\wedge}\left(0.5^{*} \mathrm{n}-3\right)+\left[\mathrm{X} . / 10 .{ }^{\wedge}(\mathrm{n}-6)\right]^{*}(14-$ 10. $\left.\wedge^{\wedge}\right) * 14 .^{\wedge}(0.5 * n-4)+$

$[\mathrm{X} . / 10 . \wedge 4]^{*}\left(14-10 .^{\wedge} 2\right) * 14+\left[\mathrm{X} . / 10{ }^{\wedge} 2\right]^{*}\left(14-10 \wedge^{\wedge} 2\right)$

Taking $\left(14-10 \wedge^{\wedge} 2=-86=-2 * 43\right)$ common and rearranging to get:-

$\Longrightarrow \mathrm{X}-43 * 2 *\left(\left[\mathrm{X} . / 10 .^{\wedge}(\mathrm{n}-2)\right]+\left[\mathrm{X} . / 10 .^{\wedge}(\mathrm{n}-3)\right]+\left[\mathrm{X} . / 10 .^{\wedge}(\mathrm{n}-4)\right]+\left[\mathrm{X} . / 10 .^{\wedge}(\mathrm{n}-\right.\right.$

6)] $\left.++\left[\mathrm{X} . / 10 .^{\wedge} 4\right]+\left[\mathrm{X} . / 10 .^{\wedge} 2\right]\right)$ 
Clearly this is divisible by 43 if $\mathrm{X}$ can be expressed as $\mathrm{X}=43 * \mathrm{~L}$ where $\mathrm{L}$ is a natural number Case 12: For $\mathrm{K}=15, \mathrm{~N}=17$; hence (iii) becomes

$\Longrightarrow \mathrm{X}+\left[\mathrm{X} . / 10 \wedge^{\wedge}(\mathrm{n}-2)\right]^{*}\left(15-10 .^{\wedge} 2\right)^{*} 15 .^{\wedge}\left(0.5^{*} \mathrm{n}-2\right)+\left[\mathrm{X} . / 10 .^{\wedge}(\mathrm{n}-4)\right]^{*}\left(15-10 . .^{\wedge} 2\right)^{*} 15 .{ }^{\wedge}\left(0.5^{*} \mathrm{n}-3\right)+[\mathrm{X} . / 10 . \wedge(\mathrm{n}-6)]^{*}(15-$

10.^2)*15.^(0.5*n-4)+.....

$\left[\mathrm{X} . / 10 .^{\wedge} 4\right]^{*} 15^{*}\left(15-10 .^{\wedge} 2\right)+\left[\mathrm{X} . / 10 .^{\wedge} 2\right]^{*}\left(15-10 .^{\wedge} 2\right)$;

Taking $(15-10 . \wedge 2=-85=-17 * 5)$ common and rearranging to get:-

$\Rightarrow \mathrm{X}-17 * 5^{*}\left(\left[\mathrm{X} . / 10 \wedge^{\wedge}(\mathrm{n}-2)\right]+\left[\mathrm{X} . / 10 .^{\wedge}(\mathrm{n}-4)\right]+\left[\mathrm{X} . / 10 .^{\wedge}(\mathrm{n}-6)\right]+\right.$

$\left.\left[\mathrm{X} . / 100^{\wedge} 4\right]+\left[\mathrm{X} . / 10{ }^{\wedge} 2\right]\right)$ by 17

Clearly this is divisible if $\mathrm{X}$ can be expressed as $\mathrm{X}=17 * \mathrm{~L}$ where $\mathrm{L}$ is a natural number

\section{Number Generator Method}

This method is based on the reverse principle of determining the divisibility tests of numbers. It consists of generating solutions from first order Diophantine Equations ( $\mathrm{n}$ variable linear equations) whose coefficients are determined from the pre-requisite stated rules and the solutions are subjected to certain constraints.

Mathematically it is stated as

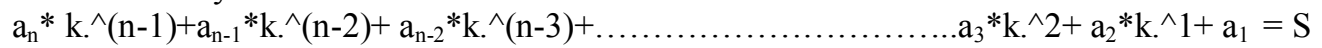

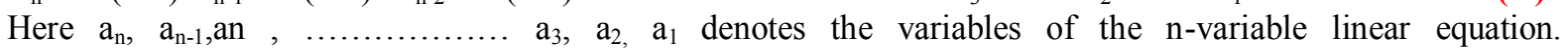
$K . \wedge(n-1), K . \wedge(n-2), K{ }^{\wedge}(n-3) \ldots \ldots \ldots \ldots \ldots \ldots \ldots \ldots$ denotes the multiplying coefficients of each of the variables where the value of $\mathrm{K}$ is determined form for the corresponding values of $\mathrm{N}$ from table 1(a) \& 1(b). The value of S depends on the value of $\mathrm{N}$ while the value of ' $\mathrm{n}$ ' (number of compartments depends on the number of $2 * n$ or $(2 * n-1)$ digits in the number \& is determined as $\mathrm{S}=\mathrm{N} * \mathrm{~L}$ where $\mathrm{L}$ is a natural number while $\mathrm{N}$ is the number for which the divisibility is to be checked.

Tables 1(a) \& 1(b) impose the following constraints on the Number Generator equation:-

- For all values of $\mathrm{k}$, a fixed value of $\mathrm{N} \& \mathrm{~L}$, the value of an must satisfy:-

$\mathrm{a}_{\mathrm{n}}<\mathrm{S} . /\left(\mathrm{K} .^{\wedge}(\mathrm{n}-1)\right)$ where $\mathrm{n}$ denotes the number of compartments

- To generate solutions containing at most $2 * n$ digits, $a_{\mathrm{n}} \sim=0$ for all $\mathrm{n}$

- If ' $h$ ' is a solution to the number generator equation such that $a_{n}=h$, then $\max \left(a_{n}\right)=99 \& \quad \min \left(a_{n}\right.$ )$=0$.

- If the value of $a_{n}$ is a single digit number, a zero is prefixed before it . For instance if $a_{n}=9$, it is represented as 09 and not simply 9.

Consider that for $\mathrm{n}=5$; if solutions are: $-\mathrm{a} 5=\mathrm{A}, \mathrm{a} 4=\mathrm{B}, \mathrm{a} 3=\mathrm{C}, \mathrm{a} 4=\mathrm{D}, \mathrm{a} 5=\mathrm{E}$, the entire solution is represented as $\mathrm{a}_{5} \mathrm{a}_{4} \mathrm{a}_{3} \mathrm{a}_{2} \mathrm{a}_{1}=\mathrm{ABCDE}$

AN EXTENSIVE APPLICATION

$-[4],[6]$

Code Encryption: - An extension of the Number Generator Method has been made to encrypt codes transferred from the sender to the receiver where the receiver is aware of the parameters used by the sender. The code generation takes the following into consideration

- The sender generates a code using the equation:-

$a_{n}{ }^{*} k . \wedge(n-1)+a_{n-1} * k \cdot \wedge(n-2)+a_{n-2} * k . \wedge(n-3)+\ldots \ldots \ldots \ldots \ldots \ldots . . a_{3} * k . \wedge 2+a_{2} * k . \wedge 1+a_{1}=S$

Where $\mathrm{S}=\mathrm{L} * \mathrm{~N}$ as defined earlier in (3),

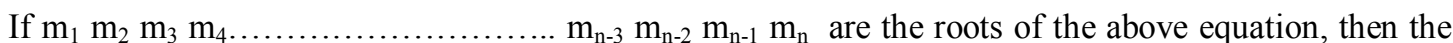
generated solution is the code: - $m_{n} m_{n-1} m_{n-2} m_{n-3}$ $\mathrm{m}_{4} \mathrm{~m}_{3} \mathrm{~m}_{2} \mathrm{~m}_{1}$

- The input equation is known only to the sender.

- The receiver however must be apprised of the parameter used by the sender.

- The sender hints the receiver regarding the values of $\mathrm{N}$, the multiplying factor $\&$ the set information which is denoted by the notation $\operatorname{Set}(\mathrm{X}, \mathrm{a}[\mathrm{n}][\mathrm{m}])$. This contains all the codes sent by the sender to the receiver.

- The receiver generates the input equation used by the sender.

COROLLARY 2:- The term a[n][m] does not denote an array, the following are denoted:-

$\mathrm{N}=$ Coefficient

$\mathrm{K}=$ Multiplying Factor corresponding $\quad$ to $\quad \mathrm{N}$

of

$-[5]$

the receiver

factors of the number of solutions

sent by the sender to

$\mathrm{n}=$ product of composite solutions $\mathrm{m}=$ number of prime factor $\mathrm{s}$ of the 
BASIS :- The set function $(\Psi(\mathrm{a})[\mathrm{n}][\mathrm{m}])$ derives its foundation from the famous Euler's Totient Theorem where the value $\Psi(\mathrm{a})$ is calculated using Euler's Totient Formulae

\section{Implementation Technique}

The implementation is based on the known parameters.

The receiver receives this information and verifies the following:- Whether the codes sent in by the sender verify the equations and verifies these from the information. The number of codes received by the receiver is in accordance with the number of codes sent in by the sender. From the information $\operatorname{set}(\mathrm{x}, \mathrm{a}[\mathrm{n}][\mathrm{m}])$, the receiver generates the number of codes that he has received. The receiver employs the Euler Totient function in order to encrypt the given codes.

\section{Illustration}

Putting N=47 \& $\mathrm{n}=5$ gives $\mathrm{k}=6$ and setting $\mathrm{l}=1296$, (4) becomes:-

$1296 a_{5}+219 a_{4}+36 a_{3}+6 a_{2}+a_{1}=60912$

We have the following solution table generated using MATLAB:-

\begin{tabular}{|c|c|c|c|c|}
\hline$a_{5}$ & $\mathrm{a}_{4}$ & $\mathrm{a}_{3}$ & $\mathrm{a}_{2}$ & $\mathrm{a}_{1}$ \\
\hline 45 & 12 & 0 & 0 & 0 \\
\hline 45 & 11 & 6 & 0 & 0 \\
\hline 45 & 11 & 3 & 12 & 36 \\
\hline 42 & 25 & 27 & 14 & 24 \\
\hline 42 & 25 & 27 & 12 & 36 \\
\hline 36 & 66 & 0 & 0 & 0 \\
\hline
\end{tabular}

If it is assumed that only 6 out of the total codes are selected, the using the validation of the number generator method we get the solutions as:-

$\mathrm{x} 1=4511031236$

$\mathrm{x} 3=4225271236$

$\mathrm{x} 4=4512000000$

$\mathrm{x} 5=4511060000$

The encoder (the sender) sends these generated codes to the receiver along with the set information:$\mathrm{N}=47, \mathrm{l}=1296$, $\operatorname{Set}(\mathrm{x}, \psi(\mathrm{a})[\mathrm{n}][\mathrm{m}])$ which in this case is denoted as :-

$(47,1296,2[\Phi][2])$

The value of $\psi(a)$ is calculated as:-

$\Psi(\mathrm{a})=\mathrm{a} *\left(1-1 . / \mathrm{j}_{1}\right) *\left(1-1 . / \mathrm{j}_{2}\right) *\left(1-1 . / \mathrm{j}_{3}\right)$ $*\left(1-1 . / \mathrm{j}_{\mathrm{n}}\right)$

Where $\mathrm{j}_{1}, \mathrm{j}_{2}, \mathrm{j}_{3} \ldots \ldots \ldots \ldots \ldots \ldots \ldots \ldots \ldots \mathrm{j}_{\mathrm{n}}$ denotes the prime factors of a. If no prime actors exist it is denoted as $\Phi$.

Consider that the sender send 120 codes to the receiver, using Euler's Totient function

$\Psi(120)=32$,

If there are 5 terms in the equation \& 120 has 3 prime factors with 4 as the least composite factor, the set information becomes:- $\operatorname{Set}(5,32[4][3])$.

\section{Merits/Demerits:-}

- It will enable the sender to check the authenticity of the data sent by him/her to the receiver.

- The receiver can check that:-

$>\quad$ Any of the codes that have been either inserted or deleted .

$>\quad$ Any interchange of digits in the codes will be detected after verification in the required equation. However the codes suffer some serious drawbacks.

- $\quad$ The codes eliminated or tampered by an intruder cannot be restored.

- Data Protection \& non -repudiation is not ensured.

\section{Conclusion}

The compartment method provides an extensive but a tedious methodology to determine the divisibility of selected primes. Infact this method can be extended to selected composites as well but the same has been omitted . Via programming in $\mathrm{C} / \mathrm{C}++$, the compartment method has aimed to find its vitality. An extensive extension to the Number Generator method and in cryptography has enabled the 


\section{Acknowledgements}

Firstly I would like to acknowledge the concentrated \& relentless efforts of my mentor Dr. Nilam without whom the completion of this paper would have been unmanageable. Considering the fact that the stated references have assisted me in the development of this paper, I would also like to attribute my grueling sessions of self-experimentation \& verification of the divisibility tests of 7 and other fixed set of primes that have assisted in laying the backbone of the paper. Its exclusive extension to the Number Generator Method \& Cryptography has proved to be a boon in its extended application and aimed to prove its practicality.

[1]. Self Realization of Divisibility Methods.

\section{References}

[2]. Verification \& Testing of Divisibility Methods

[3]. Divisibility Theory in Integers (Elementary Number Theory by David M. Burton $2^{\text {nd }}$ Edition)

[4]. Cryptography using RSA technique(Rivest,Shamir,Adleman(1978))

[5]. Euler Totient Theorem(Elementary Number Theory by David M. Burton $2^{\text {nd }}$ Edition)

[6]. Number Theoretic Functions(Elementary Number Theory by David M. Burton $2^{\text {nd }}$ Edition)

[7]. Afrah M Ibraheem,Ahlam J, Lazem(2014) 'Acts freely on Prime \& semi-primer near Rings' IOSR Journals ,Vol-10,Issue 3,pp 4548 